\title{
Guidelines for the conservation of cultural heritage buildings for tourism development along Sue Suk Road, Prachuabkirikhan, Thailand
}

\author{
D. Suephakdee \\ Silpakorn University, Thailand
}

\begin{abstract}
The aim of the proposed guidelines for the conservation of cultural heritage buildings for tourism development is to seek answers for the following: "What is the statement of significance of the vernacular shophouses along Sue Suk Road, Prachuabkirikhan?" and "How to conserve the vernacular architecture in this area?" This paper portrays the Cultural Heritage Building guidelines with regard to locally appropriate tourism development and conservation. The guidelines contain examples of the adaptive use of shophouse architecture and its integration into the tourism scheme, as well as recommendations regarding the improvement of facilities within the setting.

Keywords: cultural heritage building, vernacular architecture, conservation, tourism development, adaptive use, guideline, sustainable.
\end{abstract}

\section{Introduction}

In order to take advantage of the positive elements of tourism and, at the same time, reduce and minimize the negative impacts, guidelines are needed for conservation and tourism development in a sustainable way where attention is paid to the cultural aspect of tourism activities.

The study of local shophouses along Sue Suk Road which is situated next to the Prachuab Bay beach indicates how simple living and traditional lifestyles are preserved by the older generations, thereby rendering them unique. Community life and local culture still survive in this area, which has interesting histories and backgrounds and possesses an architectural aesthetic all its own. 
Visitors can start touring the road from the Royal Thai Air Force base, Wing 5 gate (Manao Bay) and continue up the road until reaching Chong Krajok Mountain (Prachuab Bay) (see fig. 1).
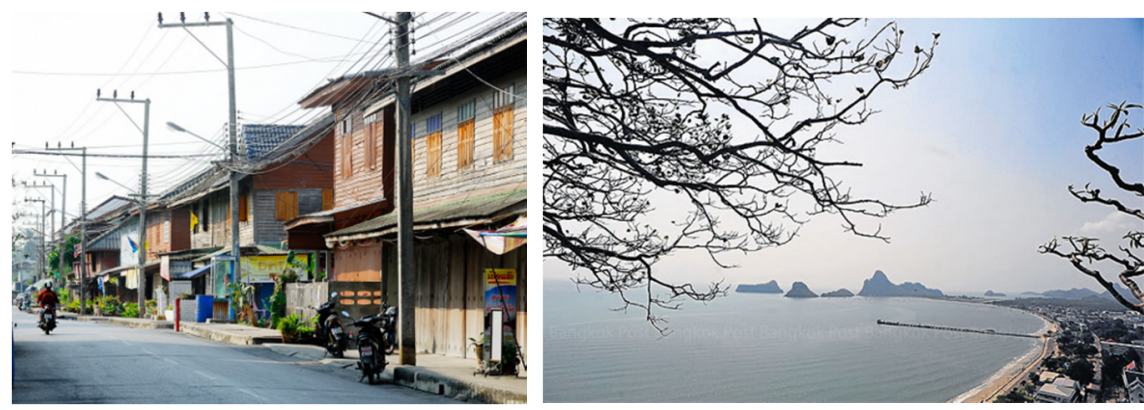

Figure 1: The road from the Royal Thai Air Force base, Wing 5 gate (Manao Bay) to Chong Krajok Mountain (Prachuab Bay). (Photographs taken by the author on 28 January 2015.)

\section{The statement of heritage significance of the vernacular shophouses along Sue Suk Road}

\subsection{The historical importance in association with the relationship to local history of the place and building}

Sue Suk community is the 1.5 kilometre historical town street of Prachuabkirikhan. This community is situated parallel to the coastal road of Prachuabkirikhan bay. Others attraction places, such as the Wing 5, Noi Bay, Prachuab Bay and Manao Bay are nearby.

2.2 The importance of a place in demonstrating rarity and uniqueness: its architectural characteristics identifying its culture and living pattern in the past through to the present

The historical, cultural and aesthetic values give Sue Suk community its uniqueness.

2.3 The importance of a place in exhibiting the principal characteristics or the representative nature of a place or object as part of a class or type of places

Sue Suk Road is a major fish market and was the trading centre of Prachuabkirikhan province in the past. The physical characteristics of Sue Suk community reflect the trading culture along Prachuab bay. The shophouses show the continuous and living community's life from earlier generations to the present. 


\subsection{The importance of a place in exhibiting good design and aesthetic characteristics and in exhibiting a richness, diversity and unusual integration of features}

The over 100-year-old Thai wooden shophouse style along with the landscape remains mostly intact.

\subsection{The importance of a place in demonstrating social and cultural association}

The shophouses are still in use and show the living conditions of people in relation to their environment, social structure and their local culture [1].

\section{Resources}

Prachuabkrikhan is a three-bay town comprising Noi Bay, Prachuab Bay and Manao Bay. It possesses coastal areas with a beautiful scenic environment, and is full of natural resources.

\subsection{Social networks}

Social networks occur due to a complete ecological system. A "relatives" system creates bonds that eventually evolve into a village community, and at a wider level, cultures create bonds among people [2]. Time and space are important tools in making the community stronger. Changes in the physical environment are also an important factor affecting social networks.

\subsection{Educational system}

Local wisdom and craftsmanship are considered to be valuable knowledge bases of the community, which should be preserved and developed for creating jobs, better health, and better living conditions. Knowledge of society and culture has gradually been instilled in the community. The transfer within the community occurs from the daily lives of family members and depends on their experience [2].

\subsection{Beliefs and values systems}

The beliefs and values that have developed in the community from generation to generation are behaviour control mechanisms, ensuring that people adopt the proper manners; promoting a higher consciousness.

\subsection{Tourism community characteristics}

Sue Suk community, which has the potential to be developed into a tourism community possesses the following characteristics: 
1. A community with natural surroundings.

The community has beautiful natural surroundings with a beautiful panorama including mountains, valleys, beaches, as well as flora and fauna.

2. A community with economic activities.

People in this community are engaged in the following activities: fishing, agriculture, handicrafts, etc.

3. A community with traditional arts and culture.

Culture and arts are applied in the day-to-day activities of the community in the form of ritual ceremonies, cultural attractions, etc.

4. A community with traditional architecture.

The community has a unique architecture, in terms of both the interior and exterior of its buildings, including the scale, size, model, construction, material, color, and decoration, all of which cannot be found in any other area.
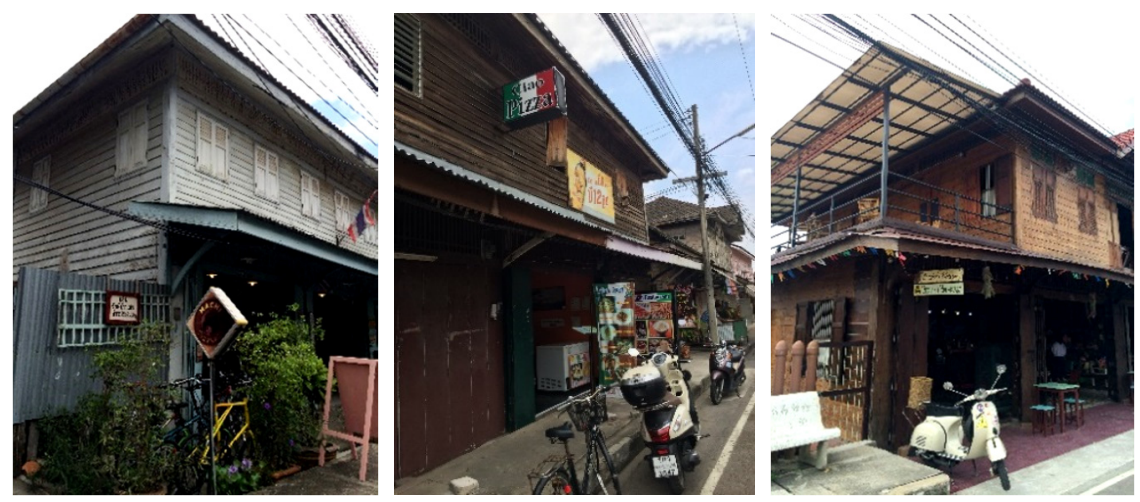

Figure 2: Along the road there are great shops and markets scattered throughout the street, such as a coffee and bike shop, Italian restaurant and guesthouse. (Photographs taken by the author on 28 January 2015.)

\section{Problems of the local community}

Local residents do not understand and are unaware of the value and uniqueness of their built heritage. Often the use of modern materials unfortunately leads to the loss of local knowledge and traditional methods of construction. Members of the younger generations do not understand why they should be preserved or why traditional materials and techniques should be used. Also, it is difficult to find craftspeople skilled in the traditional techniques of woodcarving and plastering. Other reasons put forth include: the durability of modern materials and the perception that renovations can be completed more quickly and be less labourintensive with modern materials. 
The ideal conserved community is one in which the people have good quality living conditions with an authentic culture and physical conditions. This outcome will truly be provided when the people have the opportunity to continue their authentic way of living. People have to understand the values of their community so they will agree to protect and conserve the architecture and land from the change caused by unsustainable development projects. Moreover, the community needs the local authorities to support their conservation plan as well as giving protection from inappropriate development.

This outcome is still a hope, the hypothesis being that the community will remain the authentic living, cultural and physical conditions. The important problem is the weakness of the people in community. In order to strengthen their power we need to solve the three main problems as follows:

1. The government has to support the community by assuring the locals of a minimum price for their produce/products.

Besides fishery and agriculture, the community itself is the people's main cultural asset; one that has accumulated in value throughout its long and distinguished history, and from which they can profit from in a positive way. In order to do so, the government has to encourage the people in community to promote eco-tourism and home-stays for tourists as additional alternatives.

2. Take precautions regarding the impact from tourists by educating villagers and visitors alike about community-based tourism.

Educate people in the community to understand the value of their cultural heritage.

3. Build a strong community-based organization.

In every aspect that concerns the survival of their community people in with other stakeholders. The villagers need to have a sense of place in their community, so they are able to recognize different places and the different identities of a certain place. This is important in terms of orientation and even of survival. As Harvey Cox states: "The sense of continuity of place is necessary to people's sense of reality" [3]. Also Edward Relph states that "It seems a commonplace that almost everyone is born with the need for identification with his surroundings and a relationship to them, with the need to be in a recognizable place. So sense of place is not a fine art extra, it is something we cannot afford to do without" [4].

The community needs the active involvement and support of local authorities to maintain their traditional economy and build a stronger organization within the community. In this case, direct democracy is needed, together with the need to vote for the right representatives for the leadership of the local authority [5].

We may not be able to avoid unsustainable tourism development projects that would impact vernacular shophouses in the area. It is important, however, to educate people in the community to understand the value of their community and to inform tourists about cultural norms and acceptable behaviour in an effective way. 


\section{Threats and conflicts}

There are the negative impacts of tourism on the exchange and development of culture as follows:

First, it is possible that the cultural environment will be polluted, and that there will be an unprofitable impact on both the tangible and intangible elements of heritage, especially where tourists are coming in.

Tourist flow, if not well managed, would lead to the commercialization and vulgarization of the local cultural identity and national culture for the purpose of making money. This can be seen clearly in the organization of festivals anytime, anywhere; in terms of the willy-nilly modification of old architecture, cultural performances, in terms of the rehabilitation and preservation of the local heritage which fail to follow the original blueprint.

The commercialization and vulgarization of culture, normalizing both the tangible and intangible elements of local heritage can only satisfy tourists in a fleeting manner, but can deeply wound the nation's pride in its culture, in the heritage bequeathed by our ancestors. Sooner or later, this will lead to degradation of hospitality and of the sustainable development of tourism.

Other matters to which attention should be paid are the cross-breeding of cultures, imitation of the lifestyles of foreign tourists, as well as the undermining of morality and traditions, which in turn will which lead to moral decay, etc.

\section{Example of the adaptive reuse of local shophouses for tourism development}

\section{House no. 272 Sue Suk Road}

After the 2011 floods, fleeing the capital and fulfilling a long-cherished dream, Kulphong Narknoi and his wife moved to Prachuabkirikhan and took over an old wooden house belonging to his uncle. Getting by on the proceeds from selling good-quality bicycles, doing bike repairs on the side and serving homemade pastries, cakes and coffee, the owners are also music lovers and sell jazz and bossa nova CDs. This type of shophouse has a hip-shaped roof with traditional cement roof tiles. The perfect form and proportion of this type should be preserved as an early historical reflection of the local architectural heritage (see fig. 3).

\section{House no. 238 Sue Suk Road}

This grandma bed and breakfast used to be a souvenir shop. Today the owner has turned it into small hotel and coffee shop. The special characteristics of this type of building then come from a mixing of design pattern and roof form, hip or gable of mixed type, including interior functions, by the taste of occupants. This type of shophouse shows originality of the local in creativity and sophistication, by using different traditional orders and ornaments of shophouse, then remixed them (see fig. 4). 

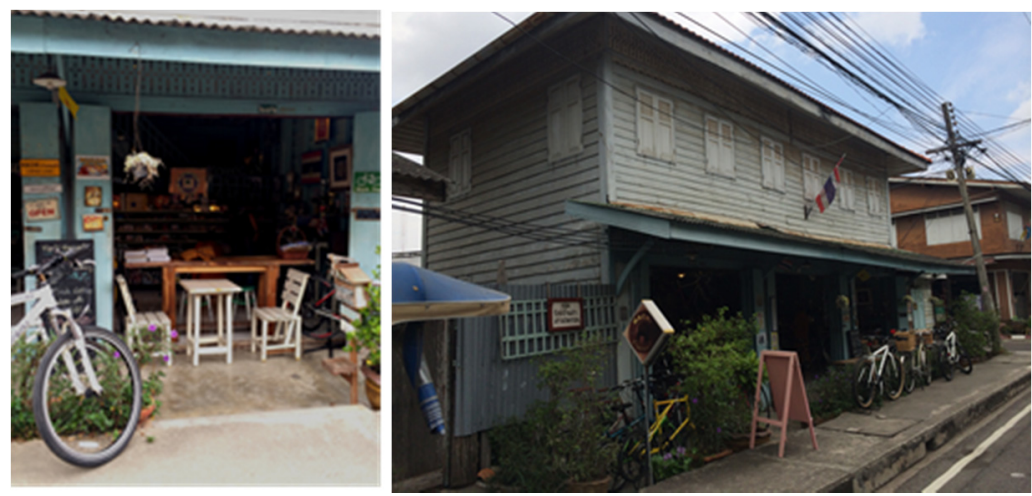

Figure 3: Hachi, coffee and bike shop; the building is more than 90 years old. (Photographs taken by the author on 28 January 2015.)
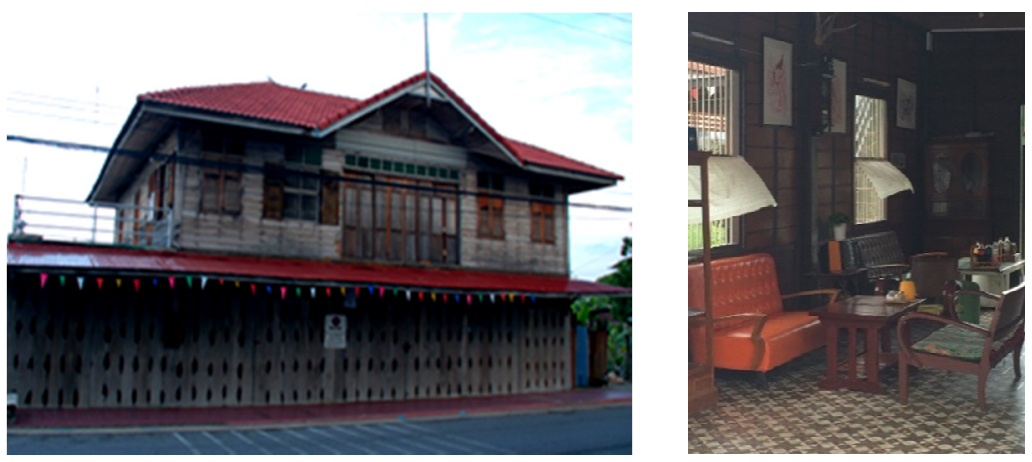

Figure 4: Grandma bed and breakfast where traditional economic activities are very much still alive. (Photographs taken by the author on 28 January 2015.)

\section{House no. 172 Sue Suk Road}

Suang Heng shop belonged to Miss Sudarat Prachuasupakit's grandfather. In the past it used to be a small hotel for salesmen and the train travellers. Nowadays, the third generation turned it into a classic retrospective coffee shop (see fig. 5). This is a special type of shophouse because of its location on the corner of the road. It was built on a particular plot shape, so its floor area was not expanded in simple rectangular shapes, which created a special hip roof form that did not come from square box outlines. Three sides of the first floor used folding doors, which make it look more spacious and luminous when fully opened. The second floor's continuous decorated roof pieces were made simple for the pattern but look elegant. 


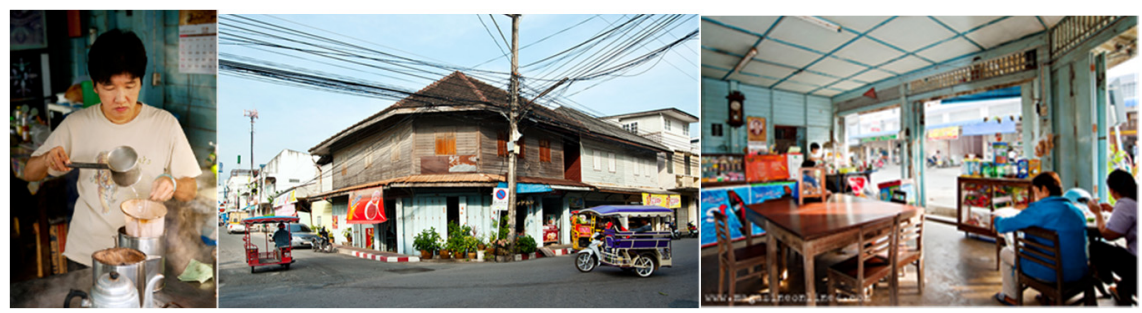

Figure 5: The retrospective coffee shop at the corner of Sue Suk Road. (Photographs from www.magazineonline4.com, accessed on 21 December 2014.)

The majority of the old shophouses in the Sue Suk community are owneroccupied, and hence are generally better cared for, even though an increasing number are sadly falling into decay. This example indicates that the movement has several dimensions, including that of cultural identity, as well as the physical conservation and economic revitalization of the site.

The project showed how modern comforts could be accommodated for by traditional shophouses without detracting from the historic fabric, and how restoration could be accomplished using traditional materials and techniques.

\section{Guidelines to resolve tourism problems in the community}

Several organizations in the community have been operating based on a bottom up process which studies the dimensions of community to government in place of the old system of government to community or a top-down process in order to stimulate and raise awareness for conservation and development by its residents under important conditions as follows:

Academic experts should not become excessively involved in community management and must allow people in the community to play the main role in several decision-making processes because they are in the best position to understand the ways of life in the community.

External assistance must be controlled at an appropriate ratio, so people in the community will be largely self-reliant and not use money as the main tool for resolving problems [5].

Resuscitation must be both tangible and non-tangible, involving, for example, the physical restoration of temples and local shophouses along with the community's history, local songs, cuisine, and local languages.

Communities will be allowed to choose tourists through management or by specifying appropriate outlines to suit their way of life, such as specifying rules or issuing community regulations that tourists must obey and follow while they are in the community, such as dress codes or helping with the maintenance of tourism resources. 


\section{Manual for guidelines regarding building improvement and design}

1. Install electric cables underground. The electric cables in front of the façade of shophouses and across the street are a tangled mess; inappropriate installation may create an eyesore within the area.

2. Improve the pedestrian walkway by using old-style paving tiles and plants.

3. The appropriate design of street lamps and street furniture. It is recommended that the lamp design be installed next to the building's façade, with a decorative cast-iron bracket adapted from the original ornamentation found on the building.

4. Clear the frontal façade of advertising boarding (see fig. 6).
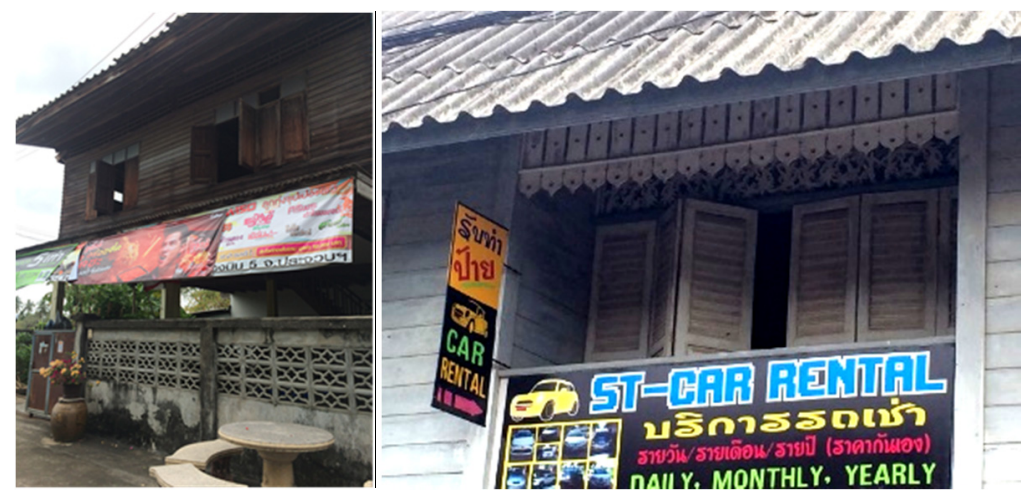

Figure 6: The façade of the shophouse is blocked by the advertisement board. (Photographs taken by the author on 28 January 2015.)

\subsection{Producing roof materials or alternative materials for roofing}

The establishment of a study project for the creation of modeling materials, particularly roof materials, is recommended. This will include the study and production of effective substitutes for original-style roof materials, specific materials and structural elements being hard to find on the market.

\subsection{Suggestions regarding the elements of original façade design of building development guidelines}

The authenticity of the doors, windows and advertisement signage which are important elements of vernacular shophouses along Sue Suk Road should be kept (see fig. 8).

1. The community center provides free architectural services for residents who are repairing their historic properties within the conservation district. A list of materials and craftsmen needs to be compiled, and a local organization established that will provide a manual encouraging more people to follow the building development guidelines. 

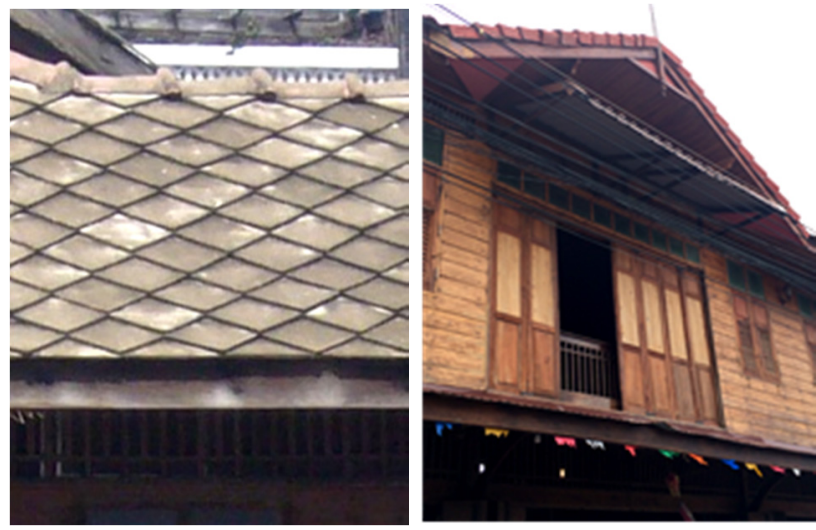

Figure 7: Roofs of shophouses that still retain the original old style roofing tiles. (Photographs taken by the author on 28 January 2015.)
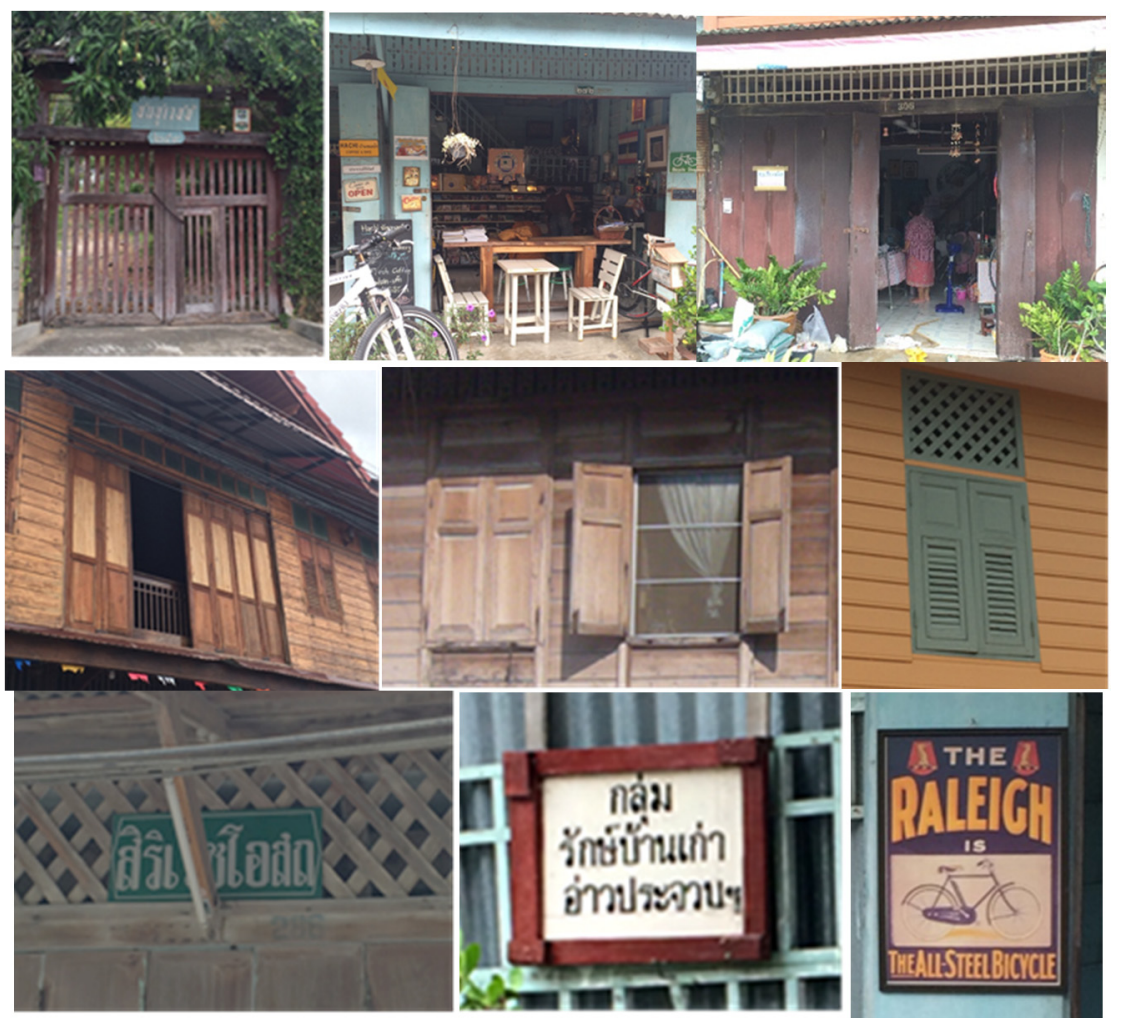

Figure 8: Examples of old-style doors, windows and advertisement signs that have been in existence since the construction of the shophouses. 
2. The sample guidelines, in the form of illustrations and additional recommendations regarding conservation and tourism development for both the shophouse and its setting, is to be practical enough for the local community to use as an effective tool to negotiate for, or initiate, the government-funded (or privately funded) projects relating to their living environment. This should at least ensure the improvement of basic facilities to match their newly conserved environment, and at the same time serve the development of tourism in the area.

\section{Summary}

These examples of project create an effective tourism development guideline for the conservation of the vernacular shophouse community along Sue Suk Road, derived from the physical data survey, the community's attitude and selfevaluation of the tourism value related to shophouse conservation of Sue Suk community. The proposed of encouraging tourism policy that benefits the local community, not only the physical conservation but especially for socio-cultural value of the place and the genuine resource for sustainable cultural tourism.

\section{References}

[1] Criteria for Assessment of Cultural Heritage Significance, Criteria adopted by the Heritage Council on 7 August 2008 pursuant to Sections 8(1)(c) and 8(2) of the Heritage Act 1995, State Heritage Office, Government of Western Australia.

[2] Buasai Silaporn, Local powers, Community Research Analysis, Bangkok, The Thailand Research Fund, B.E. 2547.

[3] Harvey Cox, The Restoration of a Sense of Place, Ekistics 25, 1968, pp. $422-424$.

[4] E. Relph, Place and Placelessness, Research in Planning and Design Series; editor Allen J Scott, Pion Limited, 207 Brondesbury Park, London NW2 $5 \mathrm{JN}$.

[5] Chatthip Nartsupha, Theory and Concept of the Economy of Peasant Communities, Bangkok, 1997. 